\title{
Young Children's Journey into a World of Play with Open-Ended Materials: A Case Study of the Creative Play Club
}

\author{
Monirah A. Al-Mansour ${ }^{1}$ \\ ${ }^{1}$ King Saud University, Saudi Arabia \\ Correspondence: Monirah A. Al-Mansour, King Saud University, Saudi Arabia. E-mail: amonirah@ksu.edu.sa
}

Received: August 10, 2018

Accepted: September 21, 2018

Online Published: November 27, 2018

doi:10.5539/ies.v11n12p117

URL: https://doi.org/10.5539/ies.v11n12p117

\begin{abstract}
This study is mainly based on conducted naturalistic descriptive observation of 13 children ages 6-8 years using open-ended materials in their play at the Creative Play Club (CPC). The research carefully examines and analyzes how four boys and nine girls in the CPC used open-ended materials in their play over 8 weeks. One aim was to evaluate changes in the quality of play over time. A second aim was to analyze the influence of various factors on children's social and nonsocial play behaviors. Those factors were the materials' characteristics and affordances and the social activity setting. The research gave special attention to the possible influences that flatten expression in play and those influences that might reignite play expression within or across CPC sessions. The research generated evidence that children's drawing, manipulating objects, and reflecting are meaning making. Interpretations of data were guided by an activity setting model, affordance theory, and a multimodality and meaning-making conceptual framework. The main findings were that the CPC and the case study are good conduits for exploring the possibilities and challenges that emerge from children's experiences with open-ended materials in play with other children.
\end{abstract}

Keywords: child's play, case study, creativity

\section{Introduction}

The value of play with open-ended materials in early childhood was recognized a long time ago. Much of our understanding of the value of play has originated from Piaget (1962), Vygotsky (1978), and Bruner (1990), who focused on the role of play in children's development. They saw children as active explorers of their worlds. With each new encounter or interaction, children are able to discover new meanings, and thus develop more complex understanding and skills.

Children are intrinsically motivated to manipulate, explore, test, and learn as they encounter activities and situations that provide such opportunities. In acknowledging the importance of play, Bruner (1990) showed that children need to be physically active and to have firsthand experiences that offer small sequences that build or scaffold their learning. He also stressed that play needs a purpose.

The value of play with open-ended materials can be recognized when watching children play with things other than toy products, such as found items or recyclable materials, as they manipulate them in ways the materials are not intended to be used. This observation leads some researchers to ask the question: Is purchasing objects and toys necessary to facilitate play for our children? Researchers Adele Diamond and Deborah Leong do not think so. They claim that the best kind of play costs nothing, and that imagination is the only thing that is really required (Bodrova \& Leong, 2001; Spiegel, 2008).

Children naturally use anything — sticks, dirt, water, pots, lids, and any other random materials - to build, construct, and play. These children are immersed in authentic play that engages them physically, emotionally, mentally, and socially (Mcdonald, \& Breuing, 2018; Miller, Tichota, \& White, 2009). Authentic play, according to the existing literature, must be pleasurable, enjoyable, spontaneous, flexible, and voluntary; it must involve active engagement and freedom, have no extrinsic goals, and contain elements of make-believe (Brown \& Vaughn, 2009; Garvey, 1977; Hirsh-Pasek \& Golinkoff, 2003).

The goal of this study was to explore how children use open-ended materials in their play over time and to determine whether it is possible to evaluate changes in the quality of a child's play over time. This study also included observation of the influence of the characteristics of the materials and their affordances on children's 
social play behavior. Evidence of meaning making through drawing, manipulating objects, and reflecting was collected over eight sessions. Therefore, the following research questions have been generated:

How do young children interact and make meaning with open-ended materials, and what are the consequences?

Many cross-cultural research scholars exploring children's play highlight the importance of culture-specific activities in structuring the environment in which children's social interactions and play activities take place (see Farver, 1999; Göncü, Tuermer, Jain, \& Johnson, 1999). My research at the CPC was designed at a natural setting of a children's school, with the children in the CPC incidentally coming from nine different backgrounds. Having participants coming from different racial and ethnic backgrounds shaped the club setting and created what those authors called peer culture. Having the children from different racial and ethnic backgrounds makes for a particularly diversified peer culture. Therefore, the materials that have been created match the diversity of the participants and to make the interactions more smoothly (see Figure 1).

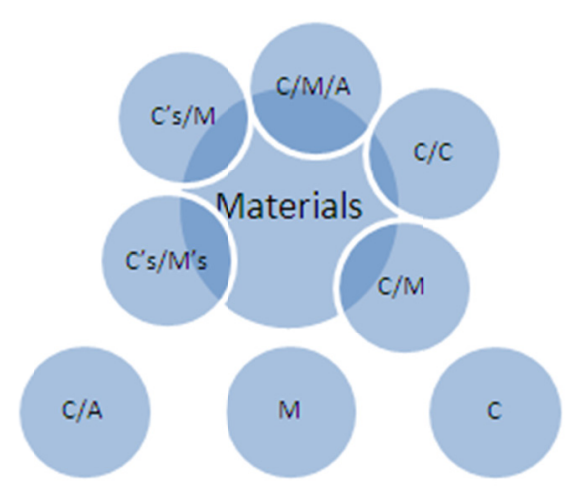

Figure 1. Types of interactions at the CPC

To be a member of a particular culture would have a psychological meaning. However, being a member of a particular culture growing up in a particular community would also contribute to the individual, which would lead to different psychological meaning (Gauvain, 1995). The cultural diversity of the CPC brought a fruitful structure, along with a unique meaning to that activity setting. Dunst et al. (2001) defined an activity setting as a "situation-specific experience, opportunity, or event that involves a child's interaction with people, the physical environment, or both, that provides a context for a child to learn about his or her own abilities and capabilities as well as the propensities and proclivities of others" (p. 70).

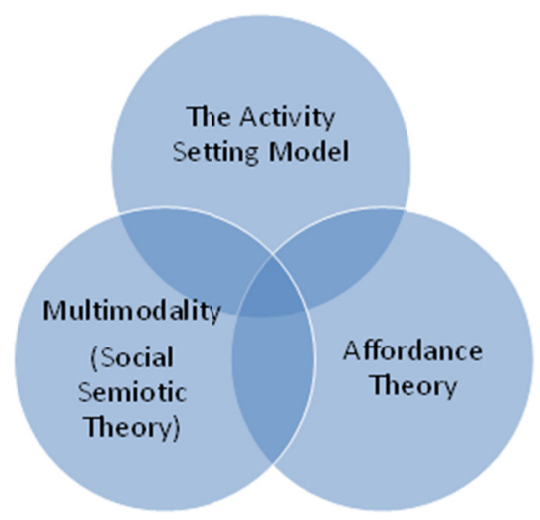

Figure 2. Intertwined theories that give a deep understanding of children's play and interaction with the surroundings

The activity setting model that was proposed by some scholars (e.g., Farver, 1999; Weisner, Gallimore, \& Jordan, 
1988) was also proposed in my research as a means of understanding how children's play behavior is mediated through their routines. According to Farver, this model is a basic unit of analysis in the sociocultural perspective. According to Gallimore and Goldenberg (1993), "Children's activity settings are the architecture of their everyday life and the context of their development" (p. 315). It is a useful tool for understanding the peer culture brought to the specific setting that was influenced by each individual's relevant skills and behavior. This model is derived from several viewpoints, including Vygotsky's (1978) model of socially mediated cognition, the activity theory by Leont'ev (1981), the Whitings' behavior setting concept (Whiting, 1988), and ecological-cultural models (Super \& Harkness, 1986).

Children manipulate the things in their environment to prop up their play. Magazines, cereal boxes, milk containers, egg boxes, and many more things that we adults tend to view as items that need to go to the recycling bin are viewed as treasure in a child's hands (Drew, 2007). These materials allow children to stack, build, create, sculpt, sort, manipulate, imagine, and do endless other things. According to Kytta (2003), children's affordance preferences for things in the environment influence their play and their selection of what props up their play.

The word affordance was invented by the perceptual psychologist Gibson $(1977,1979)$ to refer to the actionable properties between the world and an actor (a person or animal). To Gibson, affordances are relationships. They exist naturally; they do not have to be visible, known, or desirable (Gibson, 1979). Gibson defines affordances as all "action possibilities" suppressed in an environment, where the potential uses of a given object arise from its perceived properties, always in relation to the actor's capabilities and interests. The concept of affordance is often linked to play value, playability, and the importance of open-ended materials (Kernan, 2007). Rather than being regarded as objects with definite known qualities, objects or materials are studied as dynamic elements in a continuous flow of activity (Costall \& Dreier, 2006). This term has been used by many researchers from an ecological perspective to seek an understanding of children's everyday life. Affordance theory has also been increasingly used within early childhood care and education research to describe the relationship between children and their environment (Kernan, 2007).

The literature on multimodality is expanding, and discussions of play can be sidetracked by the work of semioticians who are difficult to understand and highly technical. This section focuses on children's social participation and active engagement in meaning making through their play with open-ended materials and with one another. When playing, children face many naturally occurring restrictions, such as limited space given for play or limited time. However, children follow their own interests as they choose what they want to represent using available social resources. Children tend to work with the values and status that these resources and signs (i.e., the means by which people interpret and express meaning; Saussure, 1966) (Note 1) hold in that setting (Prinsloo, 2008).

To children, anything at hand is suitable as a sign-making and meaning-making resource-whether it is a stick that readily becomes a horse (Vygotsky, 1978) or the eclectic materials the children in the CPC use to build a city and tell a story. Many scholars with diverse theoretical viewpoints agree that objects shape children's play (see Garvey, 1977; Vygotsky, 1978). The question here is: how is meaning generated through play with open-ended materials? Children make meaning in a multiplicity of ways using a multiplicity of modes (Note 2), means, and materials for self-expression that are not being recognized (Kress, 1997, p. 97).

According to Bannon and Bødker (1991), human experiences are shaped by this system of signs, by tools, and by the belief that the human mind is a result of the everyday practice and processes of meaning making. Discussions about multimodality or the semiotic approach are always associated with literacy. Although literacy is not the topic of this research, multimodality provides a comprehensive approach to analyze children's engagement in sign making to better understand meaning making as they move across the modes.

Kress describes multimodality as "an absolute fact of children's semiotic practice" (Kress, 1997, p. 137). Social semiotics is defined as "a system of meanings that constitute the reality of the culture" (Halliday, 1978, p. 123). Halliday also offers an account of the nature of language use and text construction as taking in the relationship between language and culture. According to Halliday, social semiotics is defined as "interpreting language within a socio-cultural context, in which culture itself is interpreted in semiotic terms - as an information system" (p. 2).

Much current research is focused on the multimodality approach to investigate the levels and frequency of symbolism in young children's block play (Kohn \& Uhry, 2010). Kohn and Uhry adapted the multimodal social semiotic theory to broaden the view of literacy and play. Their research considered literacy as a broad interaction with symbols and representation, which includes, but is not limited to, dancing, singing, painting, play artifacts, dress-up clothes, sculpting, construction materials, and natural objects (Dyson, 2002; Whitehead, 2004). Kohn and Uhry combined qualitative and quantitative data to observe and analyze 77 block structures. Their observation of 
frequency of symbolism consists of three levels: presymbolism, first level of symbolism, and second level of symbolism. Results indicated significant differences for first-level symbolism or real objects. Children were able to multimodality encode a computer game played at home to their block play in school.

Open-ended materials (texts) are multimodal when they consist of more than one mode of meaning. Children at the CPC share a notion of values, and explore and exercise with each other the meaning-making resources in an environment that permits freedom of choice, creativity, fantasy, experimentation, and problem solving. Multimodalities take place as a combination of material forms and ways of organization created within a culture.

\subsection{The Research Gap}

The literature of multimodality that concerns children's object play and creative play is very limited. The focus is mostly on topics that are related to new media and technologies. It should be noted, though, that the major theories of multimodality have emerged during a period of rapid technological change in the past 20 years. Although the body of literature that directly relates to multimodality and child play with objects is small, by broadening my search, I have established a valuable theoretical foundation that has supported and informed the research within my article.

An additional limitation within the literature review is that it did not focus on what might be appropriate modes of representation within different cultural contexts or communities of practice, such as home and school. Another significant limitation within the literature concerns the lack of attention to how multimodality affects adults (i.e., teachers, parents, decision makers, caregivers) who are dealing with children. The literature tends to focus instead on the representational possibilities of multimodality without considering the implications.

\section{Methodology}

The study described in this paper is based on case study research. The use of case study research has a long history across many disciplines. According to Creswell (2007), case study research involves the study of an issue explored through one or more cases within a bounded system (i.e., a setting or a context). Case study research is a qualitative approach in which the researcher explores a bounded system (a case) or multiple bounded systems (cases) over a period of time. The current research represents an intrinsic case study of the CPC as an after-school program in which the focus is on the case itself. It involves 13 children from different backgrounds within a particular local school.

\subsection{Piloting Data Collection}

The initial ambition of the study was based on a descriptive observation of a multi-age group to generate data focusing on the integration of creative play with open-ended materials into the children's routine at the CPC back in the spring of 2012. Ethnographic methods were used to generate understanding and share meaning and to inform theories of human behaviors (Hughes, 2001).

The children were observed using multiple methods: written field notes, children's sketching, photographs, and video recording. The data were eventually evaluated by the author, who was present during the sessions. I asked questions and talked with the children regarding their interactions with materials as needed.

\subsection{Current Research}

Children were the main focus of the pilot study I conducted previously at the CPC. Observations made during the pilot phase raised more questions and helped focus the research. The processes to be illustrated from the pilot study were rather complex. To make them comprehensible within the scope of the research, the CPC was presented as a unique case study to be examined. That would allow me to gain a deeper understanding of the processes of change in children's play — for example, whether change can be seen across play sessions — and explore a child's meaning making as he or she plays and interacts with open-ended materials and other children. It is assumed that the case of the CPC can reveal different findings if it is conducted somewhere else with different participants.

The findings from the pilot study served as the foundation for this current study by focusing mainly on how children play creatively with open-ended materials within the CPC. The club, however, had another purpose, which was providing children the opportunity to play freely after an exhausting school day.

\subsection{Subjectivity}

In this case, the interpretation of the situations and the play scenes at the CPC could not be free from biases or subjectivity. My strong beliefs about and valuing of children's play are something I cannot hide. I have thus become worried that an unawareness of my subjectivity could negatively influence my research. When I act as an observer I did my best to avoid my subjectivity. As I was generating data, I isolated what I observed from what I felt (my personal view on the situation). I systematically monitored my own subjectivity. I had to be sure to seek 
out my subjectivity not only during data generation and analysis, but also while my research was actively in progress.

\subsection{Participants}

Thirteen young children (Note 3) ages 6, 7, and 8 years were involved in the pilot study. All attended the extended day program at the same local charter school, and all of the children's parents agreed to let them join the CPC. Table 3.1 provides a summary of the participants' backgrounds, along with some striking facts about them to give a perspective of who the study participants were. All children were in the appropriate grade level for their age. A consent letter had been given from children's parents to conduct a case study for them. Besides, an ethical letter has been given from the Institutional Review Board (IRB). The participants' information is listed in Appendix A.

\subsection{Setting}

The CPC is set at a local kindergarten through Grade 8 charter school in Central Pennsylvania. There is no preschool in the building. The school's mission and values have an international and multicultural focus, offering programs in English as a second language to help nonnative English students transition into the United States. They also help native English speakers (and any other student who had mastered the English language) adapt to another language. Currently, the school teaches Spanish, Chinese, and Turkish. In accordance with its vision, the school believes in "supporting multicultural events in school." This is seen throughout the school year, with school events such as Turkish Night, Chinese New Year, A Touch of Culture, and others. The school has also created an affiliation with a "Sister School" in China.

The school offers a rigorous academic curriculum as well as an extended day program from 3:50 p.m. to 5:15 p.m. The extended day program has more than 30 different programs, such as foreign languages, sports clubs, art and dance clubs, cultural clubs, and more, and "keeps students active and engaged until 5:15 p.m. daily."

In the CPC, children engaged in activities and play opportunities planned by children as they got the opportunity to play and interact with open-ended materials provided by the researcher. In the case study, the focus was on open-ended materials as a type of play object that can be offered to children to play with alone or with a group of their peers. There was no restriction on how children should play, and no activities were preplanned by the researcher. The CPC as a part of the after-school program took place on Mondays from 3:30 to 5:30 p.m. for 15 sessions (the program at that time was funded and used to be 2 hours in length; the time has since been reduced). Only eight sessions were analyzed from weeks 2 through 9.

In each session, the first thing to do was to clear the classroom of furniture by pushing pieces against the wall to make room for everybody to move freely. Then children were asked to find a comfortable spot on the floor and start sketching their ideas and plan their play for about 10 minutes. After that, the children got to choose any of the materials that were spread attractively in categories on the floor. Each category of materials was placed on a piece of cloth to give it definition and also to act like an invitation to children. As the children went around the piles of lids, paper towel tubes, sticks, fabrics, and so forth they tried to find props to support their preplanned ideas. Some children did not complete obvious planning prior to play time, so it took them longer to figure out what they were going to do and how to start playing than those children who planned what they were going to do. Other children also planned ahead of time but changed their plan as they went around and started exploring and manipulating the materials.

Children's play was documented and collected using multiple methods (sketching, note taking, photographs, and video recording). In this club we avoided saying "clean up" when it was cleanup time because, to some children, that means that play is over. Consequently, after an hour of play time, the children were asked to sort, categorize, collect, and put away the materials, which in itself is a fun activity. This aspect of the play time pertains to the topic at hand, such as how play with open-ended materials changes, or the ways that a child can be transformed by opportunities to play over an extended period of time.

Children were going through the same routine each session and were asked to reflect on their play during the slideshow at the end of each session. Moreover, children were engaged in an informal discussion and conversation with me, as the researcher and group leader, to discuss what happened and what they had discovered. This friendly conversation helps develop a better understanding of what has been observed.

The CPC agenda is summarized as follows:

1) Preparation: pushing all chairs and tables against the wall and spreading the materials on the floor) (5 minutes)

2) Sketching task: preplanning (15 minutes) 
3) Hands-on experience: free play with no restriction on the types of interactions, either with children, materials, or adults in the room (60 minutes)

4) Putting all the materials back in their categories (during this time I download all the pictures and get them ready for the slideshow) (3-5 minutes)

5) Slideshow, reflection, and briefing (15 minutes)

Total time $=100$ minutes

The first session was an introduction to the routine and roles of the club; then data were generated genuinely and consecutively from session 2 to session 9 . Children needed that first session to be habituated to the activity setting and nature of the club and the way of documentation (i.e., my being present with the notebook, snapping pictures here and there, and video recording). I also needed that session to pilot test my position in the room as a participant observer.

\section{Data Generation:}

The data collection for this research was based on ethnographic methods. As researcher, I was a participant observer, which gave me access to children's play in a deeper and more precise sense. I was not an ethnographer per se, but I adopted ethnographic methods. However, the approach made me realize that what seems ordinary to me may seem strange to others.

One factor that helped children to be comfortable with me was that I am not a stranger to them. I know most of them, and their parents are my friends. The children are friends of my daughter, who happened to be one of the participants. Having my own child be one of the participants did not seem to bias the research. I did my best to make it clear to my daughter and the rest of the children that we were all there to play. Mrs. Moni (as they called me) would be playing with them, but sometimes she has to write, take pictures, or help someone who needs help. My daughter has been in my play clubs or seen me in her art classes gathering data many times. So she was habituated and never acted as if she was adjusting or was having more privileges than others.

\subsection{Field Notes}

I recorded field notes, which included a chronological, non-interpretive description of the events, settings, and children; I noted the time and duration of events and recorded comments in regard to the children's reactions, impressions, and feelings toward something, if necessary. Sometimes I kept sketches of the surroundings because it was faster for me to log, or it helped me remember the situation. Furthermore, I recorded whether any difficulties occurred during observations, such as technical issues with cameras, low batteries, a forgotten charger for the laptop, or a blinking light in the room (J. Lofland \& L. Lofland, 1995; Mellon, 1990; Patton, 1990). Field note taking was a good method to document the nonverbal play behaviors during children's play time at the club.

The field notes provided comprehensive, ethnographic documentation of children's play at the CPC. The field notes were later combined with the secondary methods of recording from the video segments and photographs.

\subsection{Children's Sketching (Drawing)}

The child's drawing is still directly connected with play and presents the characteristic traits of the object in a graphic form. Drawing several objects at the same time is nothing other than a purely mechanical combination, a purely external uniting. At the second stage, the circle of the objects the child draws is extended and machines are included in the drawing. The child draws the external form in detail; the combination of separate objects has a more connected, complex character. (Vygotsky, 1998, p. 111)

Children have many messages to communicate in their various drawing activities. In the CPC their messages were sometimes related to their play activities and sometimes not. Light (1985) stated that drawing acknowledges the social construction of meaning that children seek to convey.

\subsection{Photography and Video Recording}

In the CPC, the children's play activities were photographed and video recorded (Sawyer, 1997), and toward the end of each session (as inspired by Dr. Drew's workshops) the photographs were played back as a slideshow so the children could respond (MacNaughton, 1999). Video recording and photography have a long history in anthropology. This method, which is called visual anthropology or film ethnography, depends on the visual representations of individuals being observed (Marshall, 2006). It is also used to represent the natural event and can be used as a permanent record. The assorted forms of photography and video can be used for data collection and for organizing, interpreting, and validating qualitative inquiry.

Video recording at the CPC was a secondary and complementary resource and was mostly used to validate my 
field notes and also to catch events that I might have missed. I used my personal iPhone 5 video camera and also iMovie on my personal laptop. Both methods had pros and cons. The iPhone 5 camera was somehow better to use because I got to be closer to the event, the voice was clear enough to hear, and the device was both mobile and easy to carry. However, there were some limitations. The clip was shaky and was distracting to some children. I held the phone over my shoulder on most occasions so my voice was higher than children's voices. Although children got used to seeing me going around with the phone's camera being held that way, there were some children who showed curiosity and wanted to know why I

was holding the phone that way. I explained to them during the first session that I would be recording.

For the iMovie, I thought it would be easier to use because I wouldn't have to carry it with me. It was stationed in the corner of the classroom where almost the entire class showed magnificently. However, the method was a failure for many reasons. Although it captured the whole setting, it was confusing, and it was hard to tell who said what. The voices of children were interwoven, and the sound was low. The recorded event was occurring in a place where talking, yelling, and sometimes screaming was allowed, so the background noises and parallel conversations between children made them hard to distinguish. It was hard to recognize and understand children's talk, especially since I was interacting with 13 young children from nine different backgrounds, some of whom spoke English as a second language. The iMovie segments were therefore not good enough to be analyzed or to be included in the study.

To take photographs, I used the camera on my personal iPhone 5 because it was easy to use, provided clear pictures, and was quick to upload to my laptop. It was very important for me to use a device that I am very familiar with, that was uncomplicated, and that was easy to use in order to expedite the process of generating data-considering that I was a solo researcher who used multiple methods and was required to shift quickly according to the events. Some children asked to hold the camera to take some pictures or record some events. They were allowed to do so when they asked.

\section{Data Analysis}

There were two phases of data processing and analysis. Phase one focused on data management and the investigation of the data. Phase two focused on the social and materials interaction and environmental factors that might have affected play quality.

\subsection{Phase One-Initial Analysis}

The initial analysis focused on the investigation of data. This analysis depended on the order of the CPC's three major routines: (a) the children's sketching and preplanning for their play, which is also considered to be an avenue of expression using two-D materials; (b) the actual play time with the three-dimensional (3-D) materials, which took the longest time compared with the other two routines; and (c) reflection on the photographs of the children's play at the end of each session.

For this research I systematically studied the children's active play and related behaviors at the CPC within each session's 100 minutes of operation for eight consecutive sessions (weeks 2 through 9). First I started with the children's drawings. I organized them by dates and numbered them according to the session number. Second, I covered the children's names and replaced them with initials and used these initials for the rest of the data generated. Third, I tried to make sense of the children's preplanning, building on the multimodality perspective (Kress, 1997, 2003). I used the 2-D as a semiotic resource of expression by searching for (a) a connection between the preplanning with 2-D materials and the actual play with the 3-D materials; (b) an explanation of the children's play behavior for the entire session; and (c) any connection to what sparks group creative play and whether individual preplanning has anything to do with sparking the theme of play in such sessions.

Then I went down to the second major part of the initial analysis to make sense of the information gathered from the first part. This investigation involved examining my field notes, photographs, and video segments. My analysis of the field notes, transcribed selected video segments, and photographs was carried out by manually and visually searching for identifiable codes (i.e., units of analysis), categories, and general themes. Data were divided into major categories: (a) the peer culture and the shared meaning-making practices, subdivided into sets for drawing, constructing, socializing, and playing, and represented or tagged by the plan or topic of each session; (b) gender comparison; (c) different levels of social interactions, and materials interaction effects; and (d) enjoyment.

Every method has its biases. Using a diverse set of methods helps overcome these biases. The various methods, if they are put together, are complementary, allowing the researcher to cross-check and discover new information (Whyte, 1977).

The steps taken to process and analyze the data are part of more general ethnographic (i.e., case study) procedures 
aimed at highlighting more generally (a) the meaning of actions in the CPC and (b) the way in which children explore, experiment, and play using various modes to construct, create, and represent the world, often while engaging in social interaction with peers or with a teacher or another adult or adult figure.

\subsection{Phase Two Analysis}

The initial analysis made the second phase of analysis a lot easier. This phase of analysis focused on the social and materials interactions and environmental factors that might have affected play quality. I used the figures provided at the end of each session (shown in Chapter 5) to analyze the types of interactions for that session and to situate play within the children's experience. I also was able to draw some examples from the CPC to represent children's social and materials interaction, meaning making, and play behavior. For me to record a child's interactions in the figure, the child has to be involved in a play scenario that lasts even for a short period of time, whether solo, with partners, or with materials, and that has a beginning and an end. Also the different interactions that were recorded were either narrative interactions (with or without materials) or silent narrative interactions (with or without materials).

Social interactions at the CPC, as explained in Figure 2 in the literature review, consist of eight types of interactions. Social interactions were divided into groups A and B. It is very important to note that there is no difference between the two groups; they were divided as such for easier coding and understanding. Four types of interactions with materials were observed.

\subsection{Summarizing Session Actions}

I used narrative description when taking field notes so I could account for the behaviors of the participants during the sessions of the CPC when the focus was on how open-ended materials were being used (Johnson et al., 2014). Complementary aids were photos, drawings, and video streams. In the following subsection, I will discuss the main findings in light of theoretical background raised in the earlier section.

\section{Discussion}

The main findings of my research were that the Creative Play Club and the case study of it constitute a good conduit for exploring the possibilities and challenges that emerge from children's experiences with open-ended materials and with other children. The findings are presented by themes that emerged from the data analysis. Those themes are (a) the peer culture and the shared meaning-making practices subdivided into sets for drawing, constructing, socializing, and playing, and represented by the theme of each session; and (b) different levels of social interaction and materials interaction effects

\subsection{Journey of Play with Open-Ended Materials at the CPC}

\subsubsection{Session 1-Introduction}

It was the first day of clubs in the after-school program at the local charter school. When I first entered the room, I noticed that the children, who had been in clubs for the after-school program in the past, already seemed familiar with this type of situation. It was a natural setting for them. The author conducted 6 sessions and gave one session as an example.

\subsubsection{Session 2-Getting Familiar}

\subsubsection{Theme}

Preparation time went smoothly. Children helped with pushing the chairs and spreading out the materials. Having an assistant who was assigned to this club helped a lot in making the preparation process go faster. I was able to spend less time on direction; it seemed that everybody knew how to start the club and what to expect. We sat and talked for a minute to refresh the protocols of the club. The children showed excitement and started drawing for about 10 minutes. During this time, the assistant and I finished the laying out of materials. As "stage manager," I had to make sure we had an open area for play, enough materials, and enough time, by arranging the environment so play could occur (Jones \& Reynolds, 2011).

The actual play time with 3-D materials consisted of a lot of exploring, messing about and manipulating objects and materials, with no obvious or specific theme. Two of the boys (Leandro and James) were building a tower using wooden blocks. Amanda was on her own, silently building a wide building using wooden blocks. Edna was exploring some of the materials on the floor. She asked what one of the materials was for. I told her this is normally used to clean monitors, but "it is yours now and you can use it the way you want to." She smiled and left. Throughout the sessions Edna liked to ask questions and was curious to know about the functionality of things before using them. I found that to be on the path toward a higher quality of play. 
Yakov was wandering around solo, sometimes standing up and sometimes sitting down. He saw the tower that Leandro, James, and now Yadon were constructing together; he stood by the construction with no comments, looking at it, then he smiled and left for the uncarpeted area. He sat down on the floor and then kneeled down for a while. Then he moved back to the carpeted area again and roamed around without touching any of the materials on the floor. He repeated this behavior many times during the session, which attracted my attention. I had this conflict inside me, whether to be a facilitator and step in to see what was going on, or just stay back, observe a little bit more to try to read and understand the children's cues, and give Yakov a chance to make a decision. I really did not know at that point why Yakov did not participate, but he did not show signs of being bored. To me he was exploring his options and he needed time.

Irene focused on small objects from nature, such as stones and seeds, which she lined up. She also collected detergent lids, filled them up with seeds, and lined them up. Figure 5 shows Irene exploring by manipulating the assorted lids. She smelled one of the lids and said to me: "It smells like you!" I answered: "Really? That is interesting!" Then she hugged me and left. My initial interpretation of this was that Irene seemed to have no plan for what to do with these materials; she was just messing around with them. But the question that often came to my mind was, how would I know if she was just messing around with materials? Wasn't it possible that what she was doing was a starting point to her play line?

Alana, Rebecca, and Piper were playing imaginatively with fabrics and trying them on around their waists and shoulders. When Alana was asked what you want to be, she said: "I don't know!" However, Rebecca and Piper said they wanted to be the queen. Later on they both also pretended to have a cast on their arm. They wrapped a scarf on each hand and Rebecca said: "I got hurt, I have a cast, I am pretending!" Piper was jumping and faked whining with pain.

\subsubsection{Social Interaction}

In this session, solo play and exploration were noticeable. Irene, Yakov, Rhonda, Amanda, Ellen, Alana, Edna, Rebecca, and Piper were mostly playing solo with different types of materials. Leandro, James, and Yadon were playing together as a group with one type of material (wooden blocks).

Amanda and Ellen, Rhonda and Edna, and Alana and Edna participated in parallel play for a short time. Although Rebecca and Piper were seen together a lot in this session, they were not playing with each other; they were playing side by side. Rebecca was a dominant player and had a stronger personality, and Piper was mostly imitating and following Rebecca. Piper was not seen to initiate or interact with other children. She was mostly interested in whatever Rebecca was doing.

Kendra and Cassie were absent. Yakov remained an observer for the entire session. A few times he came closer to the group of boys but did not initiate or get involved in their play (see Figure 3 for more details).

\subsubsection{Materials Exploration and Interaction}

The majority of children at the CPC were playing with one material at a time, though a few times the children mixed materials. All of the children explored and manipulated all of the materials on the floor, including Yakov, who did not show any excitement about manipulating or interacting with the materials. In this session, the children mostly explored and played with the wooden blocks, assorted lids, and scarves. Edna showed an interest in finding the actual functionality of things by asking, "What is this?" "What is this for?" "What do you do with this?"

During this session, the girls' interactions with materials were for short periods of time. When they interacted with a material, they created a scenario that went along with it, as in this example. Piper brought a detergent lid filled with seeds and presented it to me.

Piper: This is for you.

Me: What is this?

Piper: It is your drink. Be careful, it is hot.

Me (pretending it was too hot for me and making a sound effect).

Piper: Not that hot!

Me: Is it warm?

Piper: Yes! Then Piper left to explore more things on the floor and began another narrative. (Field notes, video, S2, January 30, 2012.) 


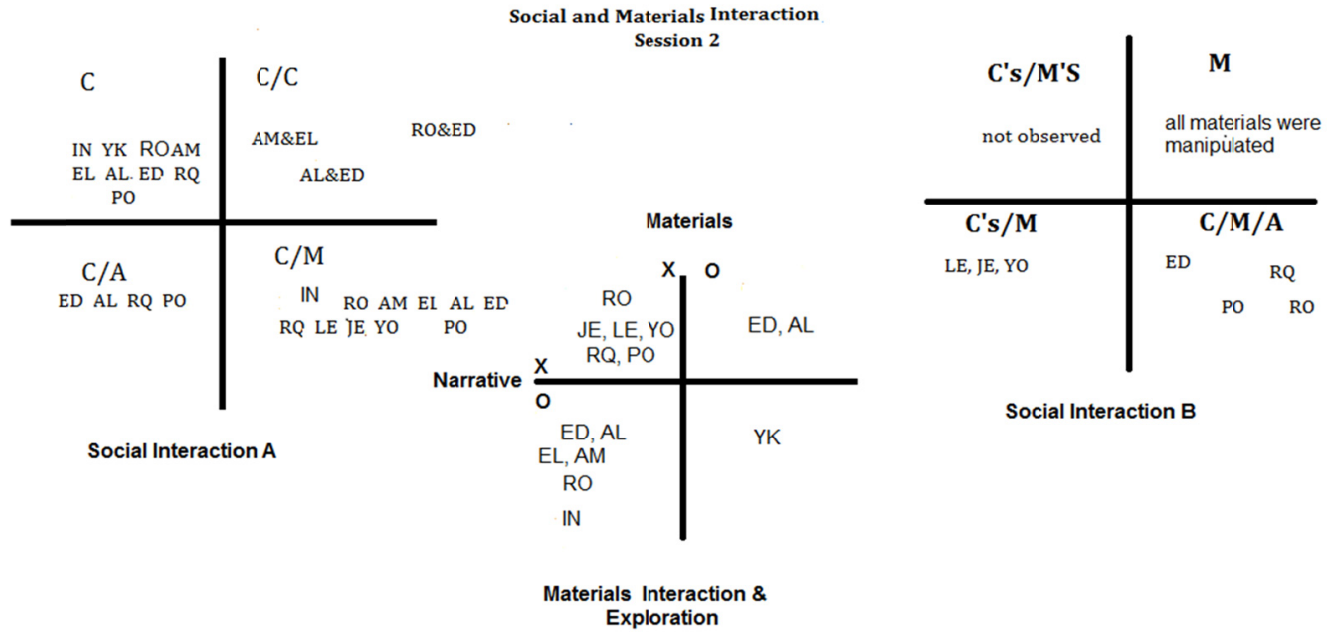

Figure 3. Social \& Materials Interaction-Session 2

Session 2 Gallery

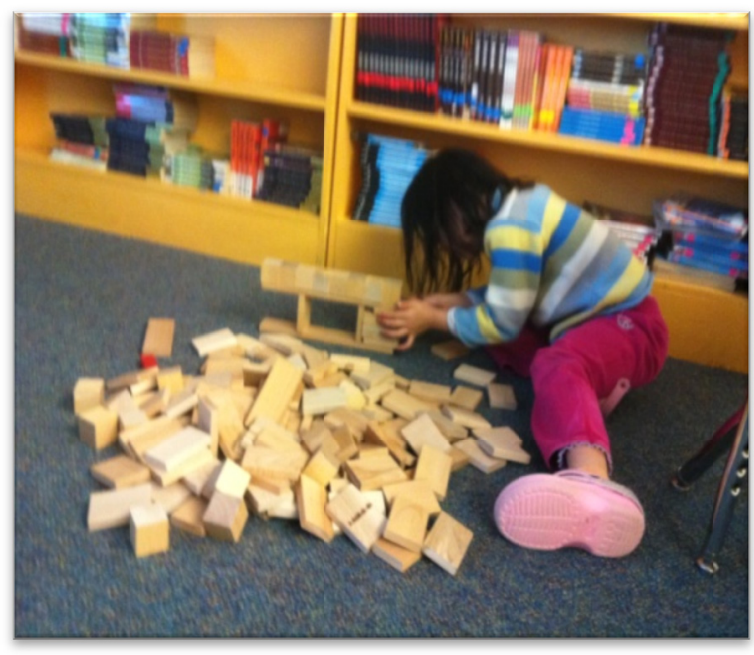

Figure 4. Amanda building with wooden blocks

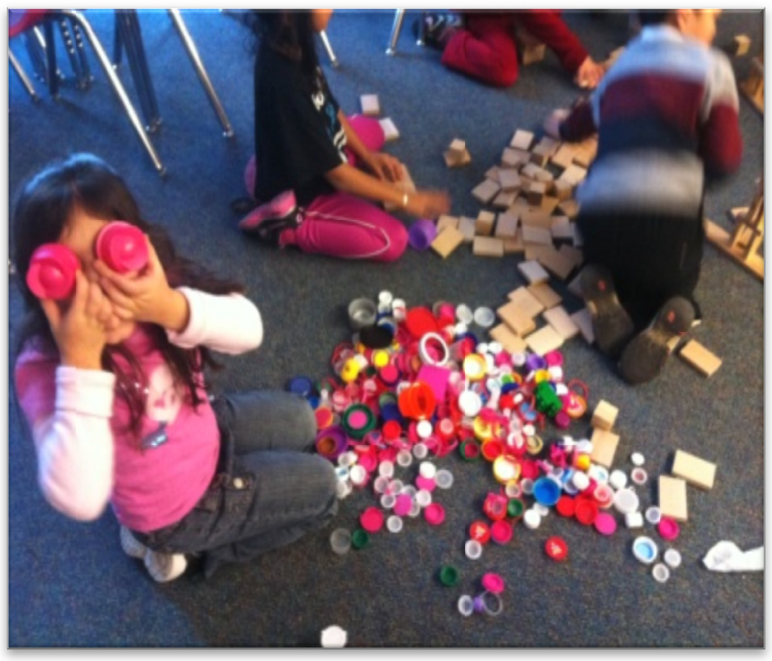

Figure 5. Irene manipulating assorted lids 


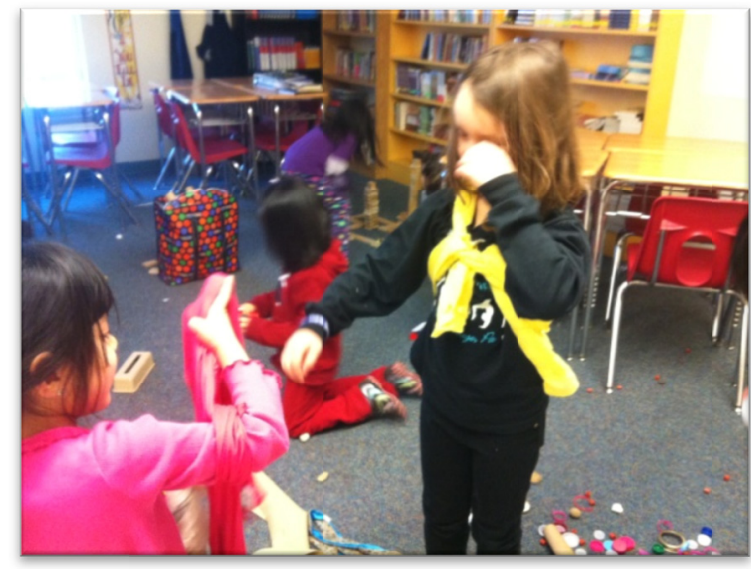

Figure 6. Cooperative play with fabrics

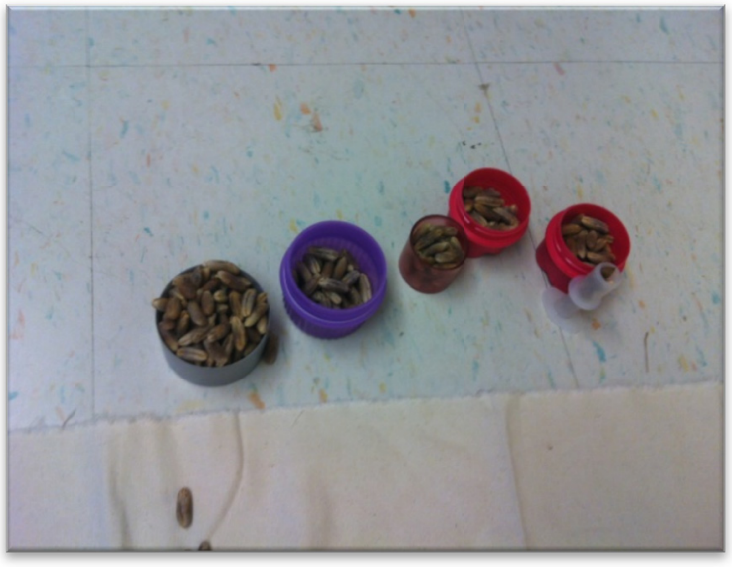

Figure 7. "Hot beverages" that had been prepared for me by Piper and Rebecca

\section{Conclusion}

This ethnographical study demonstrates that children like to play, and it is an important aspect of their daily lives. Play is the fundamental way children learn about themselves and the world. Children explore the world by playing and interacting with what they discover in their environment. The forms of play that I present and discuss in this article are similar to what Corsaro (1997) calls fantasy play, in which children create imaginary worlds in a spontaneous and improvisational manner. It is also similar to sociodramatic play (Wood \& Attfield, 2005), which involves cooperation and verbal interaction between children as they play with objects and create roles.

This case study has shown how activity settings, the uniqueness of the members of the group, and the availability of play materials can influence children's play - the type, quality, or intensity and complexity of play, as well as the people with whom children play. As shown throughout many occasions in the Creative Play Club, children's own contributions influenced and transformed the features of the activity setting, that is, the CPC. For example, one child sparked an idea for the day and it turned out to be the theme of the session. Rhonda summed it up one day during reflection time at the end of a session. She said: "One person wants to play and everybody wants to play." A group of girls shouted: "Yeah!" The answers to all of our wonders are out there; it only requires listening to children's voices and paying attention to their body language through play.

The reflection time also helped me understand some of the puzzles. In Irene's case of withdrawal in the third session, she showed discomfort through the multiple modes of expression, that is, body movement, gaze, crouch position (head down between her knees), and so on. She acted out something that was bothering her that she did not necessarily want to discuss in words.

Many incidents at the club also showed how an assumption could be incorrect. At times, with closer attention and careful examination, I found out something was completely different from what I first assumed, and most of the time it was unexpected. For a while, I thought Amanda and Ellen were English language learners, students who have English as a second language; I also assumed that Leandro, James, and Yadon were speaking limited English, but that was not true. They are just calm children. The literature shows that Asian child-rearing customs discourage children from expressing their own opinion or asserting themselves, especially if those ideas differ from the family. Asian children tend to be observers in front of authoritative figures so as to learn from them (Farver, 1999; Göncü, 1999). However, I would not generalize and say that all Asian children are discouraged from expressing themselves in front of adult without knowing the individual and how he or she is raised. Judging children's behavior based on what the literature tells us about their ethnic background and how children from certain cultures act and behave would be a very outdated approach. People who come from one culture are not the same. Just like the five fingers on one hand, they all come in different sizes and shapes.

Learning about individuals requires an effort. It would be easy to make an assumption that boys will be the most energetic and be everywhere in the room. In fact, the boys in the room were focused, goal oriented, and cooperative in their play. Girls, by comparison, were loud, were very energetic, and used their bodies as a material. Pretend play was noticed in their play. Even if they were playing as a group with the same theme, they had different agendas and plans to serve their play. The dog and the owner game in Session 7 was one example of this. The girls 
had the same theme in general, to play the dog and the owner, but Rhonda was trying, through her play, to make sense of how, as a Muslim, she was raised not to touch a dog. On another occasion, Alana was dealing with her two dogs, one of which happened to be Rebecca, who was the hyper dog who tried to escape from the owner. Alana wished to own a dog one day.

Children at the CPC created their own peer culture, even as they brought with them their own culture and tried to make meaning of the world they live in to help them adapt. Through cooperation, all modes at the CPC were treated as one connected cultural resource for making meaning by members of a social group at a particular moment in a particular setting.

A very important point about the activity setting analysis is that it addresses the ethnocentric biases by allowing researchers to investigate and look into children's development in context, according to Farver (1999). He explains that by examining diversity in an individual's experience, researchers can isolate what is similar to their own and start to understand the roles of rearing and where people are coming from that determines behavior.

Children's engagement was mediated through artifacts and guidance that ranged from playing to observational opportunities and sometimes explicit instruction. By participating in cultural activity mediated as such, children negotiate the meanings of their culture, accepting, rejecting, or transforming them. Thus, sociocultural views do not see development as predetermined. The contributions and goals of the participants are what determined the developing mind within a dynamic context.

The CPC routine and agenda did not remain the same for the entire time as anticipated, particularly in the way it affected children's play quality and engagement at the club. Toward the end of the CPC, we faced some changes and challenges that were beyond our control. The modified agenda for the club considered the affordances of the environment where children play, that is, how children use their environment for play and activity purposes (Gibson, 1979). The concept of affordances includes both the environment and the individual, meaning that the affordances are unique for each individual and correspond with the individual's ability, strengths, skills, motivation, and so forth. The affordances of the environment of the CPC consisted of what it "invited" children to do.

In addition, the children participating in the CPC theoretically had a lot of freedom of choice to do what they wanted to do with materials. However, in practice, the club was regulated by some school rules that restricted our freedom to go beyond the space or time offered or to take any furniture out to make more space for children to play freely. What constitute the prospective affordances available in a child's play environment are the characteristics in the environment that influence what the child is able to actualize and make use of. This means that affordances influence how a child will be able to actualize his or her propensity to play freely. Moreover, the child's propensity to play freely and interact with the materials and others will influence the child's engagement and anticipation to join in. It is a two-way scenario.

\section{References}

Bannon, L., \& Bødker, S. (1991). Beyond the interface: Encountering artifacts in use. In J. Carroll (Ed.), Designing interaction: Psychology at the human computer interface. Cambridge, U.K.: Cambridge University Press.

Bodrova, E., \& Leong, D. J. (2001). Tools of the Mind: A case study of implementing the Vygotskian approach in American early childhood and primary classrooms (UNESCO Innodata Monographs: Educational Innovations in Action). Geneva, Switzerland: International Bureau of Education, UNESCO.

Brown, S., \& Vaughn, C. (2009). Play: How it shapes the brain, opens the imagination, and invigorates the soul. New York, NY: Avery.

Bruner, J. S. (1990). Acts of meaning. Cambridge, MA: Harvard University Press.

Corsaro, W. A. (1997). The sociology of childhood. Thousand Oaks, CA: Pine Forge Press.

Costall, A., \& Dreier, O. (2006). Doing things with things: The design and use of everyday objects. Hampshire, U.K.: Ashgate Publishing Limited.

Diamond, A., Barnett, S., Thomas, J., \& Munro, S. (2007). Executive function can be improved in preschoolers by regular classroom teachers. Science, 318, 1387-1388. https://doi.org/10.1126/science.1151148

Drew, W. (2007). Endless possibilities. Scholastic Parent \& Child, 14(6), 54. Retrieved from http://ehis.ebscohost.com/ehost/pdfviewer/pdfviewer?vid=2\&sid=0a0f001d-8956-42ea-b825-0ffff63d39c8 $\% 40$ sessionmgr14\&hid=17 
Dunst, C. F., Bruder, M. B., Trivette, C. M., Hamby, D., Raab, M., \& Mclean, M. (2001). Characteristics and consequence of everyday natural learning opportunities. Topics in Early Childhood Special Education, 21(2), 68-92. https://doi.org/10.1177/027112140102100202

Dyson, A. H. (2002). Writing and children's symbolic repertoires: Development unhinged. In S. B. Neuman, \& D. K. Dickinson (Eds.), Handbook of early literacy research (pp. 126-141). New York, NY: Guilford Press.

Farver, J. A. M. (1999). Activity setting analysis: A model for examining the role of culture in development. In A. Göncü (Ed.), Children's engagement in the world: Sociocultural perspectives (pp. 99-127). Cambridge, MA: Cambridge University Press.

Gallimore, R., \& Goldenberg, C. (1993). Activity settings of early literacy: Home and school factors in children's emergent literacy. In E. A. Forman, N. Minick, \& C. A. Stone (Eds.), Contexts for learning sociocultural dynamics in children's development (pp. 315-335). New York, NY: Oxford University Press

Garvey, C. (1977). Play. Cambridge, MA: Harvard University Press.

Gauvain, M. (1995). Thinking in niches: Sociocultural influences on cognitive development. Human Development, 38, 25-45. https://doi.org/10.1159/000278297

Gibson, J. J. (1977). The theory of affordances. In R. Shaw \& J. Bransford (Eds.), Perceiving, acting, and knowing: Toward an ecological psychology (pp. 67-82). Hillsdale, NJ: Erlbaum.

Gibson, J. J. (1979). The ecological approach to visual perception. Boston, MA: Houghton Mifflin.

Goffman, E. (1974). Frame analysis. New York, NY: Harper \& Row.

Göncü, A. (1999). Children's engagement in the world: Sociocultural perspectives. Cambridge, U.K.: Cambridge University Press.

Göncü, A., Tuermer, U., Jain, J., \& Johnson, D. (1999). Children's play as cultural activity. In A. Göncü (Ed.), Children's engagement in the world: Sociocultural perspectives ( $\mathrm{pp}$. 148-170). Cambridge, U.K.: Cambridge University Press.

Halliday, M. A. K. (1978). Language as a social semiotic. Baltimore, MD: University Park Press.

Hirsh-Pasek, K., \& Golinkoff, R. M. (2003). Einstein never used flashcards: How our children really learn and why they need to play more and memorize less. Emmaus, PA: Rodale Press.

Johnson, J. E., Al-Mansour, M., \& Sevimli-Celik, S. (2014). Researching play in early childhood. Handbook of Research Methods in Early Childhood Education.

Jones, E., \& Reynolds. G. (2011). The play's the thing: Teachers' roles in children's play (2nd ed.). New York, NY: Teachers College Press.

Kernan, M. (2007). Play as a context for early learning and development: A research paper. Dublin, Ireland: National Council for Curriculum and Assessment. Retrieved from http://www.ncca.ie/en/Curriculum_and_Assessment/Early_Childhood_and_Primary_Education/Early_Chil dhood_Education/How_Aistear_was_developed/Research_Papers/Play_paper.pdf

Kohn, L., \& Uhry, J. (2010). Naming block structure: A multimodal approach. Retrieved from http://lynnecohen.com/lynnDocs/NamingBlockStructures.pdf

Kress, G. (1997). Before writing: Rethinking the paths to literacy. London, U.K.: Routledge.

Kress, G. (2003). Literacy in the new media age. London, U.K.: Routledge.

Kytta, M. (2003). Children in outdoor contexts: Affordances and independent mobility in the assessment of environment child friendliness (Doctoral thesis, Helsinki University of Technology, Finland).

Leont'ev, A. N. (1981). Activity, consciousness, and personality. Englewood Cliffs, NJ:

Light, P. (1985). The development of view specific representation considered from a sociocognitive standpoint. In N. H. Freeman, \& M. V. Cox (Eds.), Visual order: The nature and development of pictorial representation (pp. 214-230). Cambridge, U.K.: Cambridge University Press.

Lofland, J., \& Lofland, L. H. (1995). Analyzing social settings: A guide to qualitative observation and analysis (3rd ed.). Belmont, CA: Wadsworth.

MacDonald,. M., \& Breunig, M. (2018). Back to the Garten: Ontario kindergarteners learn and grow through schoolyard pedagogy. Journal of Outdoor and Environmental Education, 21(2), 131-155. https://doi.org/10.1007/s42322-018-0011-z 
MacNaughton, G. (1999). Even pink tents have glass ceilings: Crossing the gender boundaries in pretend play. In E. Dau \& E. Jones (Eds.), Child's play: Revisiting play in early childhood settings. Sydney, Australia: MacLennan \& Petty.

Marshall, C. (2006, February). Data collection method. Retrieved from http://www.sagepub.com/upm-data/10985_Chapter_4.pdf

Mellon, C. A. (1990). Naturalistic inquiry for library science: Methods and applications for research, evaluation, and teaching. New York, NY: Greenwood.

Miller, D. L., Tichota, K., \& White, J. (2009). Young children learn through authentic play in a nature explore classroom. Based on research conducted at Dimensions Early Education Programs in Lincoln, NE. Retrieved August 15, 2011, from http://www.dimensionsfoundation.org/research/index.cfm

Patton, M. Q. (1990). Qualitative evaluation and research methods (2nd ed.). Newbury Park, CA: Sage.

Piaget, J. (1962). Play, dreams, and imitation in childhood. New York, NY: W.W. Norton. Prentice-Hall.

Prinsloo, M. (2008). Children's games as local semiotic play: An ethnographic account. In M. Prinsloo and M. Baynham (Eds.), Literacies, Global and Local (pp. 117-136). Amsterdam, The Netherlands: John Benjamins. https://doi.org/10.1075/aals.2.08pri

Saussure, F. (1966). A course in general linguistics (W. Baskin, Trans.). New York, NY: McGraw-Hill.

Sawyer, R. K. (1997). Pretend play as improvisation: Conversation in the pre-school classroom. Mahwah, NJ: Erlbaum.

Spiegel, A. (2008, February). Old-fashion play builds serious skills. Retrieved from http://www.npr.org/templates/story/story.php?storyId=19212514

Super, C., \& Harkness, S. (1986). The developmental niche: A conceptualization of the interface of child and culture. International Journal of Behavioral Development, 9, 545-569. https://doi.org/10.1177/016502548600900409

Vygotsky, L. S. (1978). Mind in society: Development of higher psychological processes. Cambridge, MA: Harvard.

Vygotsky, L. S. (1998). The collected works of L.S. Vygotsky, Vol. 5: Child Psychology (M. J. Hall, Trans; R. W. Reiber, Ed.). New York, NY: Plenum Press. (Original work written 1933-1934)

Weisner, T., Gallimore, R., \& Jordan, C. (1988). Unpackaging cultural effects on classroom learning: Native Hawaiian peer assistance and child-generated activity. Anthropology and Education Quarterly, 19, 327-351.

Whitehead, M. R. (2004). Language and literacy in the early years. Thousand Oaks, CA: Sage.

Whiting, B. B. (1988). Culture and social behavior: A model for the development of social behavior. Ethos, 8 , 95-116. https://doi.org/10.1525/eth.1980.8.2.02a00010

Whyte, A. V. T. (1977). Guidelines for field studies in environmental perception, Note 5. MAB Technical Notes Series. Paris: UNESCO.

Wolfe, J. (2002). Learning from the past: Historical voices in early childhood education (2nd ed.). Mayerthorpe, Alberta, Canada: Piney Branch Press.

Wood, E., \& Attfield, J. (2005). Play, learning and the early childhood curriculum (2nd ed.) London, U.K.: Paul Chapman. https://doi.org/10.4135/9781446280393

\section{Notes}

Note 1. Signs provide a material way of understanding how people exchange meaning irrespective of the means by which they do it. These might be the lines of drawing, the sounds of speech or the movements of gesture, and so on.

Note 2. Mode refers to a set of socially and culturally shaped resources for making meaning. Mode classifies a "channel" of representation or communication for which previously no overarching name had been proposed (Kress \& van Leeuwen, 2001). Examples of modes include writing and drawn images on the page; moving images and sounds on the screen; and speech, gesture, gaze, and posture in embodied interaction.

Note 3 . The names of the participants in this paper have been changed for confidentiality purposes. 


\section{Appendix A}

\begin{tabular}{|c|c|c|c|c|c|}
\hline Pseudonym & $\begin{array}{l}\text { Participants' } \\
\text { Initials }\end{array}$ & $\begin{array}{l}\text { Grade } \\
\text { Level }\end{array}$ & Gender & Ethnicity & Facts \\
\hline Edna & $\mathrm{ED}$ & $\begin{array}{l}\text { 1st } \\
\text { grade }\end{array}$ & Girl & $\begin{array}{l}\text { Indian } \\
\text { American }\end{array}$ & $\begin{array}{l}\text { Edna is half Indian and half American. She is being raised with } \\
\text { a heavy influence of her mother's background as Indian. She is } \\
\text { the only child from the same mother and father, but she has } \\
\text { half brothers and sisters from previous marriages from both } \\
\text { sides. She likes to ask questions. }\end{array}$ \\
\hline Rebecca & RQ & $\mathrm{K}$ & Girl & Mexico & $\begin{array}{l}\text { Rebecca is the only child of an immigrant family that moved to } \\
\text { the United States before she was born. She has a strong } \\
\text { personality. She can be stubborn. }\end{array}$ \\
\hline Piper & $\mathrm{PO}$ & $\mathrm{K}$ & Girl & China & $\begin{array}{l}\text { Piper is originally from China. She was adopted by an } \\
\text { American family when she was younger (by the age of } 4 \text { or } 5 \text {, } \\
\text { not sure when). On many occasions she talked about her life in } \\
\text { China and said that she will visit China one day. She still } \\
\text { carries some memory of her being there. Her English is not } \\
\text { fully developed. She has a hard time adapting to a new } \\
\text { situation, but once she gets familiar, she is more comfortable. }\end{array}$ \\
\hline Ellen & EL & $\mathrm{K}$ & Girl & Taiwan & $\begin{array}{l}\text { Ellen is bilingual, born in Taiwan and raised in the U.S. Her } \\
\text { English is developing. Ellen's and Amanda's families are } \\
\text { friends. }\end{array}$ \\
\hline Amanda & $\mathrm{AM}$ & $\mathrm{K}$ & Girl & Taiwan & $\begin{array}{l}\text { Amanda is bilingual, born in Taiwan and raised in the U.S. Her } \\
\text { English is developing. Amanda's and Ellen's families are } \\
\text { friends. }\end{array}$ \\
\hline Alana & $\mathrm{AL}$ & $\begin{array}{l}\text { 1st } \\
\text { grade }\end{array}$ & Girl & U.S.-White & $\begin{array}{l}\text { Alana was born and raised in the same town her parents are } \\
\text { from, which is the same town this research took place. She is } \\
\text { social, an easy-going child. }\end{array}$ \\
\hline Kendra & $\mathrm{KE}$ & $\begin{array}{l}\text { 1st } \\
\text { grade }\end{array}$ & Girl & $\begin{array}{l}\text { African } \\
\text { American }\end{array}$ & $\begin{array}{l}\text { Kendra resides in this town for the purpose of her mother's } \\
\text { education. She is the only child raised by a single mother who } \\
\text { is working on her } \mathrm{PhD} \text {. She loves attention. Kendra and Irene } \\
\text { are neighbors. }\end{array}$ \\
\hline Irene & IN & $\begin{array}{l}\text { 1st } \\
\text { grade }\end{array}$ & Girl & Pakistan & $\begin{array}{l}\text { Irene resides in this town for the purpose of her mother's } \\
\text { education. She is the only child raised by a single mother who } \\
\text { is working on her } \mathrm{PhD} \text {. Irene and Kendra are neighbors. }\end{array}$ \\
\hline Rhonda & RO & $\begin{array}{l}\text { 1st } \\
\text { grade }\end{array}$ & Girl & Saudi Arabia & $\begin{array}{l}\text { Rhonda resides in this town for the purpose of her mother's } \\
\text { education. She is the youngest of five in her family. She is } \\
\text { social with a wide imagination; she loves attention. }\end{array}$ \\
\hline Cassie & $\mathrm{CA}$ & $\begin{array}{l}1 \mathrm{st} \\
\text { grade }\end{array}$ & Girl & U.S.-White & $\begin{array}{l}\text { Cassie came in as a guest in Session } 8 \text { and decided to stay for } \\
\text { the remaining sessions of the CPC. }\end{array}$ \\
\hline Ryan & RY & $\mathrm{K}$ & Boy & U.S.-White & Ryan came to the club as a guest only for one session. \\
\hline Yadon & YO & K & Boy & Korea & $\begin{array}{l}\text { Yadon is bilingual, born in Korea and raised in the U.S. His } \\
\text { English is developing. He is shy and quiet and seems to follow } \\
\text { somebody else's plan. Yadon's, James's, and Leandro's } \\
\text { families are friends. }\end{array}$ \\
\hline Yakov & YK & $\mathrm{K}$ & Boy & Rwanda & $\begin{array}{l}\text { Yakov is the only child of an immigrant family who moved to } \\
\text { the U.S. before he was born. He seems to be cautious before } \\
\text { attempting to proceed in any new situation. He can be loud and } \\
\text { gets excited easily. He is social once he gets familiar with a } \\
\text { setting. }\end{array}$ \\
\hline James & $\mathrm{JE}$ & $\mathrm{K}$ & Boy & Korea & $\begin{array}{l}\text { James is bilingual, born in Korea and raised in the U.S. His } \\
\text { English is developing. James's, Leandro's, and Yadon's } \\
\text { families are friends. }\end{array}$ \\
\hline
\end{tabular}




\begin{tabular}{|l|l|l|l|l|l|}
\hline Leandro & LE & K & Boy & Korea & $\begin{array}{l}\text { LE is bilingual, born in Korea and raised in the U.S. His } \\
\text { English is developing. He is goal oriented and likes to plan and } \\
\text { play with others. Leandro's, James's, and Yadon's families are } \\
\text { friends. }\end{array}$ \\
\hline
\end{tabular}

\section{Copyrights}

Copyright for this article is retained by the author(s), with first publication rights granted to the journal.

This is an open-access article distributed under the terms and conditions of the Creative Commons Attribution license (http://creativecommons.org/licenses/by/4.0/). 